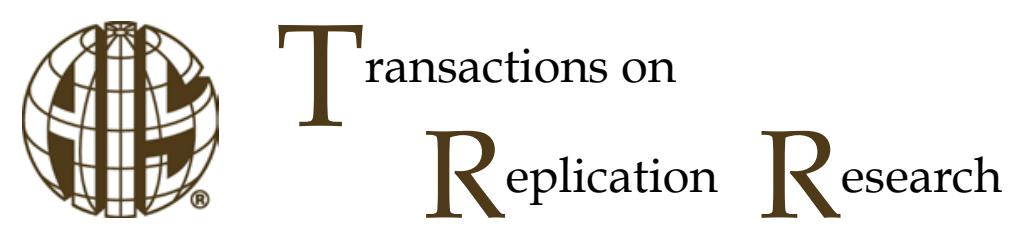

Methodological Replication

ISSN 2473-3458

\title{
How Does Guanxi Affect Intention to Share Knowledge in the US? A Replication Study
}

\author{
Jordana George \\ Department of Information Systems, Baylor University \\ Jordana_George@baylor.edu
}

\author{
Jie (Kevin) Yan \\ Department of Supply Chain, Information Systems and \\ Analytics, Dalton State College \\ jyan@daltonstate.edu
}

\begin{abstract}
:
We undertake a replication of research conducted in China, The Impact of Trust, Guanxi Orientation and Face on the Intention of Chinese Employees and Managers to Engage in Peer-To-Peer Tacit and Explicit Knowledge Sharing, originally published in Information Systems Journal. The study explores how aspects of Guanxi affect the intention to share knowledge. Guanxi is the Chinese phenomenon of a tight network or relationship, and the original research found that it influences the intention to share both tacit and explicit knowledge. The original study explored Cognitive, Affect, Face-Saving, and Face-Gaining constructs in explaining the influences on the intention to share knowledge. We look at how this study translates to a US business school to find out if any of the original constructs apply outside of Chinese culture in regards to sharing knowledge. Our study did not demonstrate any relationship with the FaceSaving or Face-Gaining aspects of Guanxi on the intention to share knowledge. On the other hand, we did find that the Cognitive construct (skills) had a positive relationship with knowledge sharing, unlike the original. Last, both studies demonstrate a relationship between Affect and knowledge sharing, as well as Guanxi (or relationship) and knowledge sharing, indicating that people who get along well and like each other are more likely to share knowledge, regardless of Chinese or US cultural background.
\end{abstract}

Keywords: Replication, PLS, Guanxi, Knowledge Sharing, Face-gaining, Face-saving

The manuscript was received 01/11/2017 and was with the authors 3 months for 2 revisions. 


\section{Introduction}

Guanxi, a cultural and social phenomenon in China, is a crucial part of business success (Park and Luo, 2001). We define Guanxi as a multi-dimensional phenomenon of relationships, social networks, strategy, exchange of favors, and a path for smooth transactions (Chen et al., 2013). Although some researchers pondered the decline of Guanxi in years past (Guthrie, 1998), it not only remains important in organizations (Chen et al., 2013), but is also an interesting aspect of Chinese workers and students abroad (Ding and Li, 2012). In our global business environment, it is critical for non-Chinese organizations and workers to understand Guanxi relationships for cross-cultural success (Murray and Fu, 2016). Another aspect of doing business in China is understanding the cultural significance of Face-Saving and Face-Gaining, known as Mianzi (Hwang, 1987). Westerners are familiar with variants of this behavior as seeking status, and address it in more subdued terms, such as "keeping up with the Joneses" or maintaining one's reputation (Washington and Zajac, 2005), but Mianzi holds greater significance in Chinese culture (Hwang, 1987). Last, there is a need for trust in organizational relationships, a topic with a great deal of literature in both the west and China (Child and Möllering, 2003; Elangovan and Shapiro, 1998; Fulmer and Gelfand, 2012; Wang et al., 2008; Zaheer et al., 1998).

Yet, how well do the Chinese concepts translate to other cultures, even when some parallels exist? Which aspects of Guanxi are easily understood outside of China and which are not? We choose to answer these questions not with a new study, but by replicating work originally done in China that explores the intention to share tacit and explicit knowledge as a result of Guanxi orientation, face, and trust. We conduct a methodological replication study of The impact of trust, Guanxi orientation and face on the intention of Chinese employees and managers to engage in peer-to-peer tacit and explicit knowledge sharing (Huang et al., 2011). We undertake this replication to determine which aspects of Chinese business orientation (i.e. trust, Guanxi, and face) are applicable in a U.S. setting among non-Chinese business school students. We find that replication provides an interesting tool to further examine our constructs in regards to knowledge management. Replication is important because replicable results are a main tenet of the scientific method (Brandt et al., 2014). Popper (2005) stated that "non-reproducible single occurrences are of no significance to science." Replications are particularly important for information systems research because they help the field evolve and grow (Dennis and Valacich, 2014; Niederman and March, 2015). In this spirit, we undertake our methodological replication.

Instead of using the term Guanxi in our study, we substitute the English term "relationship," but we use the same measurement items from the original research in this reflective construct, with the exception of one question that was deemed out of place in the western context. Guanxi is loosely equivalent to western "relationships," but is far more complex, therefore, we anticipate some effects from changing this word. We do not change the terminology for Face-Saving or Face-Gaining, or for Trust.

\section{Research Model and Hypotheses}

The constructs used include Cognition-based trust, Affect-based trust, Guanxi (Relationship) Orientation, Face-Saving, Face-Gaining, Intention to share explicit knowledge, and Intention to share tacit knowledge. Cognition-based trust involves the professionalism and skills of colleagues, while Affect-based trust is grounded in emotions, caring, and friendship. For the Guanxi construct we substitute the word "relationship" as most US students are not familiar with the Chinese term. Face-Saving, a less common term in the US, is similar to keeping up social norms and expectations, while Face-Gaining is a buildup of social capital. The intention to share knowledge is split into tacit and explicit knowledge. Tacit knowledge is knowledge which cannot be easily expressed but which may require someone to demonstrate or explain, while explicit knowledge can be explained in an accessible manner, such as user manuals or instructions (Nonaka, 1994). Table 1 summarizes the model constructs examined in this study. Figure 1 illustrates the research model and hypothesized relationships derived from the original study (Huang et al., 2011). 


\begin{tabular}{|l|l|}
\hline \multicolumn{2}{|c|}{ Table 1. Constructs } \\
\hline Model Constructs & Skills, experience \\
\hline Cognition-based trust & Emotion, caring \\
\hline Affect-based trust & Relationship, sharing, Face-Gaining, Face-Saving \\
\hline $\begin{array}{l}\text { Guanxi (Relationship) } \\
\text { Orientation }\end{array}$ & Keeping up expectations \\
\hline Face-Saving & Buildup of social capital \\
\hline Face-Gaining & User manual, written instructions \\
\hline $\begin{array}{l}\text { Intention to share } \\
\text { explicit knowledge }\end{array}$ & Not easily described, requires further explanation or demonstration \\
\hline $\begin{array}{l}\text { Intention to share tacit } \\
\text { knowledge }\end{array}$ & \\
\hline
\end{tabular}

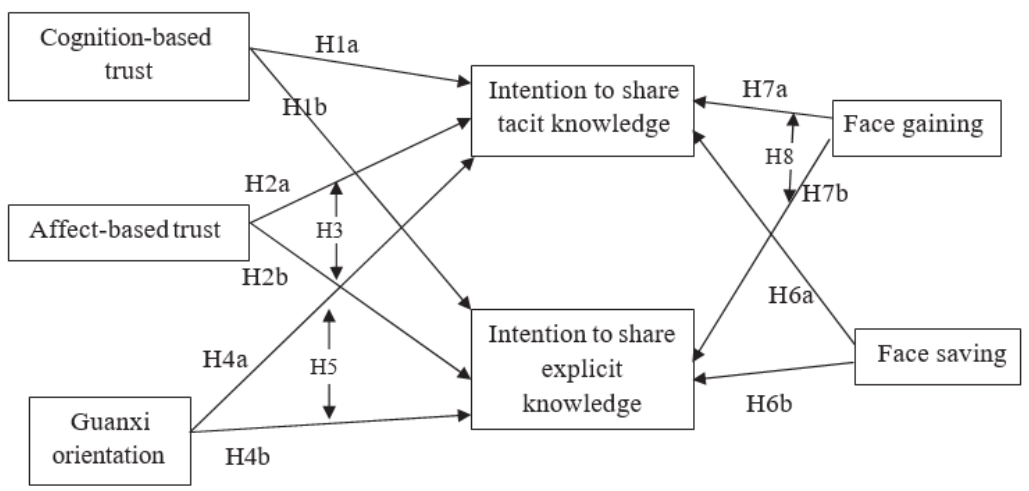

Figure 1. Model from the original study (Huang et al., 2011)

\section{Original Hypotheses:}

The original hypotheses are as follows:

H1a Cognition-based trust will have a positive effect on tacit knowledge-sharing intention

H1b Cognition-based trust will have a positive effect on explicit knowledge-sharing intention

$\mathrm{H} 2 \mathrm{a}$ Affect-based trust will have a positive effect on tacit knowledge-sharing intention

$\mathrm{H} 2 \mathrm{~b}$ Affect-based trust will have a positive effect on explicit knowledge-sharing intention

H3 Affect-based trust has a stronger effect on tacit knowledge-sharing intention than explicit knowledgesharing intention.

$\mathrm{H} 4 \mathrm{a}$ The stronger the relationship orientation is, the stronger the intention to share tacit knowledge will be.

$\mathrm{H} 4 \mathrm{~b}$ The stronger the relationship orientation is, the stronger the intention to share explicit knowledge will be.

H5 Relationship orientation has a stronger impact on tacit knowledge-sharing intention than explicit knowledge-sharing intention.

H6a Face-Saving will have a negative effect on the intention to share tacit knowledge.

H6b Face-Saving will have a negative effect on the intention to share explicit knowledge.

H7a Face-Gaining will have a positive effect on the intention to share tacit knowledge. 
H7b Face-Gaining will have a positive effect on the intention to share explicit knowledge.

H8 Face-Gaining will have a stronger impact on the intention to share tacit knowledge than explicit knowledge.

\section{Method}

A methodological replication indicates that we use the same methods as the original research but we carry out our study in a different environment (Dennis and Valacich, 2014). In this case, the original study included 204 Chinese business school students, while we use 125 US business school students ${ }^{1}$. We utilize the original measures and survey questions, with the addition of three demographic questions (the measurement items and survey questions are listed in Appendix A). We use the same method of analysis, Partial Least Squares Structural Equation Modeling (PLS-SEM). The original study used PLS-Graph software, while we use Smart-PLS. Both studies use a two-step analysis using bootstrap sampling approach to assess the measurement model, followed by analysis of the structural model (Hair et al., 2016).

\subsection{Data Collection}

We used the identical survey as the original study, albeit in English ${ }^{2}$. For sample collection, we used business school students in a medium sized Texas business school. The students were from multiple classes and some instructors offered a small amount of extra credit to complete the survey.

Out of 130 original respondents in our study, we selected 125 for inclusion as 5 records were incomplete ${ }^{3}$. Our demographic data differed than the original study as we ended up with double the number of females as males, where the original had three times as many males as females. Our median age was younger than that of the original study, as well. Last, our sample contained far more undergraduates than the original study. Table 2 summarizes the demographic data of the 125 respondents.

\begin{tabular}{|l|l|}
\hline \multicolumn{2}{|c|}{ Table 2. Demographic Data } \\
\hline Gender & Male = 43 (34.4\%); Female = 82 (65.6\%) \\
\hline Age & $18 \sim 30=80(64.0 \%) ; 31 \sim 40=19(15.2 \%) ; 40+=26(20.8 \%)$ \\
\hline Education & $\begin{array}{l}\text { High School }=6(4.8 \%) ; 4 \text {-year College }=95(76.0 \%) ; \text { College Graduate = } 15(12.0 \%) ; \text { Post } \\
\text { Graduate }=9(7.2 \%)\end{array}$ \\
\hline
\end{tabular}

\subsection{Analysis and Results}

\subsubsection{Measurement Model}

We first examined reliability and validity of the latent variables by evaluating the measurement model. Using the Smart PLS software, we ran a bootstrap with 5000 iterations to provide parameter estimates and standard errors in the sample, including path coefficients, t-values, and p-values. As this is a replication, we used the same method of analysis. The original authors used PLS for exploratory analysis and we find the same benefit in this replication study.

Table 3 summarizes the results of the evaluation of the measurement model. The values of composite reliability (CR) and average variance extracted (AVE) indicate internal reliability, or consistency. Our CR and AVE values are above the 0.7 and 0.5 threshold value, respectively, indicating good reliability (Chin, 1998; Fornell and Larcker, 1981). To assess convergent and discriminant validity, we examined the square root of the AVE for each construct and factor loadings (Hair et al., 2014). The results in Table 3

\footnotetext{
${ }^{1}$ We also conducted additional analyses where we increased the sample size to 253 . The results are shown in the Additional Analyses section.

${ }^{2}$ We substituted the term "relationships" for Guanxi and deleted the first item in Face-Saving that referred specifically to Chinese culture.

${ }^{3} \mathrm{An} \mathrm{N}$ of 125 is above the recommended minimum sample size of 122 for five independent variables at a $5 \%$ significance level (Cohen, 1992). 125 is also well above the 10x rule of thumb suggesting a minimum $\mathrm{N}$ of 50 (Hair et al., 2016).
} 
demonstrate that the square root of the AVE (in bold on the diagonal) is above the correlations of construct in both columns and rows. This supports the discriminant validity of the constructs (Fornell and Larcker, 1981). For the factor loadings, Table 4 shows that all the individual item measures load highest on its own latent variable rather than other latent variables, further supporting the convergent and discriminant validity of our measurement model (Fornell and Larcker, 1981).

Table 3. Reliability, Validity and Correlation Matrix

\begin{tabular}{|l|l|l|l|l|l|l|l|l|l|l|l|}
\hline \multicolumn{10}{|c|}{ Table 3. Reliability, Validity and Correlation Matrix } \\
\hline Construct & Mean & SD & CR & AVE & Affect & Cognit & Explic & Gain & Relat & Save & Tacit \\
\hline Affect & 5.22 & 0.93 & 0.89 & 0.62 & $\mathbf{0 . 7 9}$ & & & & & & \\
\hline Cognit & 5.52 & 0.92 & 0.94 & 0.76 & 0.53 & $\mathbf{0 . 8 7}$ & & & & & \\
\hline Explic & 5.34 & 1.02 & 0.91 & 0.83 & 0.42 & 0.44 & $\mathbf{0 . 9 1}$ & & & & \\
\hline Gain & 4.47 & 1.29 & 0.89 & 0.80 & 0.11 & 0.07 & 0.12 & $\mathbf{0 . 8 9}$ & & & \\
\hline Relat & 5.83 & 0.83 & 0.89 & 0.58 & 0.27 & 0.39 & 0.40 & 0.28 & $\mathbf{0 . 7 6}$ & & \\
\hline Save & 4.13 & 1.36 & 0.81 & 0.69 & -0.18 & -0.12 & 0.01 & -0.13 & 0.17 & $\mathbf{0 . 8 3}$ & \\
\hline Tacit & 5.60 & 0.89 & 0.90 & 0.76 & 0.55 & 0.55 & 0.59 & 0.01 & 0.37 & -0.07 & $\mathbf{0 . 8 7}$ \\
\hline
\end{tabular}

Affect: Affect-based trust; Cognit: Cognition-based trust; Explic: Intention to share explicit knowledge; Gain: Face-Gaining Relat: Guanxi orientation; Save: Face-Saving; Tacit: Intention to share tacit knowledge

\begin{tabular}{|l|l|l|l|l|l|l|l|}
\hline \multicolumn{7}{|c|}{ Table 4. PLS Factor Loadings and Cross Loadings } \\
\hline & Affect & Cognit & Explic & Gain & Relat & Save & Tacit \\
\hline Affect1 & $\mathbf{0 . 7 7 8}$ & 0.397 & 0.351 & -0.011 & 0.194 & -0.158 & 0.512 \\
\hline Affect2 & $\mathbf{0 . 8 5 2}$ & 0.422 & 0.338 & 0.246 & 0.249 & -0.194 & 0.486 \\
\hline Affect3 & $\mathbf{0 . 6 0 2}$ & 0.252 & 0.310 & 0.149 & 0.244 & -0.058 & 0.311 \\
\hline Affect4 & $\mathbf{0 . 8 7 5}$ & 0.525 & 0.328 & 0.036 & 0.259 & -0.146 & 0.429 \\
\hline Affect5 & $\mathbf{0 . 7 9 9}$ & 0.495 & 0.341 & 0.042 & 0.149 & -0.143 & 0.413 \\
\hline Cognit1 & 0.451 & $\mathbf{0 . 9 0 1}$ & 0.450 & 0.076 & 0.376 & -0.114 & 0.517 \\
\hline Cognit2 & 0.347 & $\mathbf{0 . 8 5 3}$ & 0.370 & 0.145 & 0.317 & -0.101 & 0.456 \\
\hline Cognit3 & 0.433 & $\mathbf{0 . 7 7 1}$ & 0.358 & 0.049 & 0.245 & -0.098 & 0.354 \\
\hline Cognit4 & 0.530 & $\mathbf{0 . 9 1 6}$ & 0.360 & 0.023 & 0.365 & -0.108 & 0.496 \\
\hline Cognit5 & 0.570 & $\mathbf{0 . 9 1 2}$ & 0.384 & 0.054 & 0.391 & -0.122 & 0.562 \\
\hline Explic1 & 0.440 & 0.456 & $\mathbf{0 . 9 3 1}$ & 0.114 & 0.385 & -0.013 & 0.581 \\
\hline Explic2 & 0.321 & 0.337 & $\mathbf{0 . 8 8 9}$ & 0.122 & 0.352 & 0.041 & 0.494 \\
\hline Gain1 & 0.001 & 0.054 & 0.062 & $\mathbf{0 . 8 1 2}$ & 0.247 & -0.024 & -0.020 \\
\hline Gain2 & 0.150 & 0.081 & 0.143 & $\mathbf{0 . 9 6 9}$ & 0.265 & -0.165 & 0.015 \\
\hline Relat1 & 0.198 & 0.229 & 0.267 & 0.370 & $\mathbf{0 . 6 8 5}$ & 0.232 & 0.208 \\
\hline Relat2 & 0.198 & 0.177 & 0.117 & 0.229 & $\mathbf{0 . 6 1 9}$ & 0.178 & 0.139 \\
\hline Relat3 & 0.111 & 0.316 & 0.288 & 0.209 & $\mathbf{0 . 8 1 7}$ & 0.149 & 0.274 \\
\hline Relat4 & 0.168 & 0.251 & 0.257 & 0.212 & $\mathbf{0 . 7 1 4}$ & 0.049 & 0.247 \\
\hline Relat5 & 0.297 & 0.348 & 0.421 & 0.163 & $\mathbf{0 . 8 1 2}$ & 0.107 & 0.377 \\
\hline Relat6 & 0.257 & 0.388 & 0.368 & 0.193 & $\mathbf{0 . 8 8 3}$ & 0.148 & 0.346 \\
\hline Save1 & -0.153 & -0.090 & 0.011 & -0.040 & 0.164 & $\mathbf{0 . 6 6 6}$ & -0.027 \\
\hline Save2 & -0.167 & -0.119 & 0.011 & -0.146 & 0.155 & $\mathbf{0 . 9 6 8}$ & -0.083 \\
\hline Tacit1 & 0.433 & 0.500 & 0.614 & -0.005 & 0.332 & -0.022 & $\mathbf{0 . 8 6 2}$ \\
\hline Tacit2 & 0.506 & 0.442 & 0.524 & -0.025 & 0.313 & -0.030 & $\mathbf{0 . 8 5 5}$ \\
\hline Tacit3 & 0.512 & 0.502 & 0.424 & 0.040 & 0.328 & -0.145 & $\mathbf{0 . 8 9 8}$ \\
\hline & & & & & & & \\
\hline
\end{tabular}




\subsubsection{Structural Model and Results}

Table 5 summarizes the results and tests of hypotheses and compares these with the results from the original study (differences are highlighted in bold in columns 4 and 5). The key difference lies in the relationships between knowledge sharing (both tacit and explicit) and Face-Saving and Face-Gaining.

While the original study found that both Face-Saving and Face-Gaining significantly affect individuals' intention to share knowledge (Face-Saving only affects sharing tacit knowledge), none of these relationships is significant in the context of the present study ( $\mathrm{H6a}: \beta=-0.030$, ns; H6b: $\beta=0.036$, ns; $\mathrm{H} 7 \mathrm{a}: \beta=-0.124$, ns; $\mathrm{H} 7 \mathrm{~b}: \beta=0.015$, ns). Accordingly, $\mathrm{H} 8$ is not supported either. In addition, our results show a significant relationship between cognition-based trust and individuals' intention to share knowledge (H1a: $\beta=0.292, p<0.01 ; \mathrm{H} 1 \mathrm{~b}: \beta=0.199, \mathrm{p}<0.1)$. This contrasts the original study where cognition-based trust has no impact on ones' knowledge sharing intention. Finally, while the other relationships are in line with the original study - i.e., both Affect-based trust and Relationship (i.e., Guanxi orientation) influence sharing tacit and explicit knowledge, our additional t-tests on comparing path coefficients indicate no differences in relationship strength (H3: $t=0.53$, ns; $H 5$ : $t=0.64$, ns). Table 6 summarizes the results of path coefficients comparisons. We discuss our findings further in the discussion section.

\begin{tabular}{|c|c|c|c|c|}
\hline \multicolumn{5}{|c|}{ Table 5. Results of PLS Analysis ( $N=125)$} \\
\hline Hypotheses & Coefficient & t-Value & $\begin{array}{l}\text { This Study } \\
\text { Hypothesis } \\
\text { Supported }\end{array}$ & $\begin{array}{l}\text { Original Study } \\
\text { Hypothesis } \\
\text { Supported }\end{array}$ \\
\hline H1a: Cognit -> Tacit & 0.292 & $2.94^{\star \star \star}$ & Yes & No \\
\hline H1b: Cognit -> Explic & 0.199 & $1.67^{*}$ & Yes & No \\
\hline H2a: Affect -> Tacit & 0.351 & $3.07^{\star \star \star}$ & Yes & Yes \\
\hline H2b: Affect -> Explic & 0.241 & $2.27^{\star \star}$ & Yes & Yes \\
\hline H4a: Relat -> Tacit & 0.204 & $2.33^{\star \star}$ & Yes & Yes \\
\hline H4b: Relat -> Explic & 0.244 & $2.35^{\star \star}$ & Yes & Yes \\
\hline H6a: Save -> Tacit & -0.030 & 0.32 & No & Yes \\
\hline H6b: Save -> Explic & 0.036 & 0.37 & No & No \\
\hline H7a: Gain -> Tacit & -0.124 & 1.42 & No & Yes \\
\hline H7b: Gain -> Explic & 0.015 & 0.14 & No & Yes \\
\hline Control Variables & Coefficient & t-Value & & \\
\hline Age $->$ Tacit & -0.020 & 0.26 & No & Not shown \\
\hline Age -> Explic & -0.132 & 1.61 & No & Not shown \\
\hline Gender -> Tacit & -0.019 & 0.24 & No & Not shown \\
\hline Gender -> Explic & 0.061 & 0.69 & No & Not shown \\
\hline Educ -> Tacit & -0.010 & 0.12 & No & Not shown \\
\hline Educ -> Explic & 0.097 & 1.19 & No & Not shown \\
\hline \multicolumn{5}{|c|}{ Variance Explained $\left(\mathrm{R}^{2}\right)$} \\
\hline \multicolumn{5}{|c|}{ Share Tacit Knowledge: $\mathrm{R}^{2}=43.3 \%$} \\
\hline \multicolumn{5}{|c|}{ Share Explicit Knowledge: $\mathrm{R}^{2}=32.4 \%$} \\
\hline
\end{tabular}




\begin{tabular}{|l|l|l|l|}
\hline \multicolumn{4}{|c|}{ Table 6. Results of Path Coefficients Comparison (N=125) } \\
\hline Hypotheses & t-Value & $\begin{array}{l}\text { This Study Hypothesis } \\
\text { Supported }\end{array}$ & $\begin{array}{l}\text { Original Study } \\
\text { Hypothesis Supported }\end{array}$ \\
\hline H3: Affect -> Tacit Vs. Affect -> Explic & 0.53 & No & No \\
\hline H5: Relat -> Tacit Vs. Relat -> Explic & 0.64 & No & Yes \\
\hline H8: Gain -> Tacit Vs. Gain -> Explic & N/A & No & Yes \\
\hline
\end{tabular}

\subsection{Additional Analyses}

One methodology difference between this study and the original study lies in the sample size. Our model analysis is based on 125 survey responses whereas the original study analyzed 204 responses. The relatively small sample size of this study may limit the effectiveness and power of our structural model in detecting relationship between the constructs (Hair et al., 2016). To eliminate this sample size difference and evaluate the robustness of the models, we later conducted a second-round data collection in the same business school using the same measurement scales. Another 131 students responded to our survey questions and among them 3 students' responses were discarded due to missing data, resulting in a total of $253(125+128)$ useful responses ${ }^{4}$. We then reran the PLS measurement and structural model analyses based on the combined dataset. Table 7 presents the results of structural model analyses ${ }^{5}$ and they are highly consistent with those in Table 5, confirming the results of this replication study.

\begin{tabular}{|c|c|c|c|c|}
\hline \multicolumn{5}{|c|}{ Table 7. Results of PLS Analysis ( $N=253)$} \\
\hline Hypotheses & Coefficient & t-Value & $\begin{array}{l}\text { This Study } \\
\text { Hypothesis } \\
\text { Supported } \\
\end{array}$ & $\begin{array}{l}\text { Original Study } \\
\text { Hypothesis } \\
\text { Supported }\end{array}$ \\
\hline H1a: Cognit -> Tacit & 0.303 & $4.31^{\star \star \star}$ & Yes & No \\
\hline H1b: Cognit -> Explic & 0.249 & $2.45^{\star \star}$ & Yes & No \\
\hline H2a: Affect -> Tacit & 0.287 & $4.13^{\star \star \star}$ & Yes & Yes \\
\hline H2b: Affect -> Explic & 0.372 & $4.87^{\star \star \star}$ & Yes & Yes \\
\hline H4a: Relat -> Tacit & 0.407 & $7.28^{\star \star \star}$ & Yes & Yes \\
\hline H4b: Relat -> Explic & 0.226 & 2.50 ** & Yes & Yes \\
\hline H6a: Save -> Tacit & -0.013 & 0.49 & No & Yes \\
\hline H6b: Save -> Explic & -0.006 & 0.15 & No & No \\
\hline H7a: Gain -> Tacit & -0.026 & 0.80 & No & Yes \\
\hline H7b: Gain -> Explic & 0.083 & 1.54 & No & Yes \\
\hline Control Variables & Coefficient & t-Value & & \\
\hline Age -> Tacit & -0.023 & 0.82 & No & Not shown \\
\hline Age -> Explic & -0.043 & 1.14 & No & Not shown \\
\hline Gender -> Tacit & 0.025 & 1.01 & No & Not shown \\
\hline Gender -> Explic & 0.029 & 0.85 & No & Not shown \\
\hline Educ -> Tacit & -0.004 & 0.13 & No & Not shown \\
\hline Educ -> Explic & 0.033 & 0.93 & No & Not shown \\
\hline \multicolumn{5}{|c|}{ Variance Explained $\left(\mathrm{R}^{2}\right)$} \\
\hline \multicolumn{5}{|c|}{ Share Tacit Knowledge: $\mathrm{R}^{2}=52.2 \%$} \\
\hline \multicolumn{5}{|c|}{ Share Explicit Knowledge: $\mathrm{R}^{2}=43.2 \%$} \\
\hline
\end{tabular}

$$
\left({ }^{\star} p<0.1 ;{ }^{* \star} p<0.05 ;{ }^{* \star} p<0.01 ; \text { two-tailed }\right)
$$

\footnotetext{
${ }^{4}$ We combined all the responses as the results of two-sample t-tests indicate there is no significant difference between the two sample sets.

${ }^{5}$ We also evaluated the measurement model and there is no reliability and/or validity issue.
} 


\section{Discussion and Conclusion}

Guanxi is a multi-faceted construct, with elements of strategic usage, individual and organizational applications, and a complex web of relationships, favors, and quid pro quo (Chen et al., 2013). Because Guanxi has no direct translation in English, we used the more generic western term "relationship" as a substitute for the Chinese word in our survey questions. We would expect to find some differences between the original study and our replication as a result of using this simplification of Guanxi. However, even with substituting "relationship", our replication supports some aspects of Guanxi in our non-Chinese students.

The greatest difference between the American respondents and the original study was seen in FaceSaving and Face-Gaining. These concepts, as described in the questionnaire, were not understood by some respondents and most of the others found them irrelevant in terms of sharing knowledge. However, we believe that there are aspects of Face-Saving and Face-Gaining in western culture and further research may uncover this link. For example, Darwin, the preeminent British scientist, studied the topic of embarrassment in evolutionary terms as far back as 1872, and recent research continues to uncover the role of saving face in complex personal interactions (Keltner and Anderson, 2000). Face-Gaining bears some similarities with western culture, as well. "Peer pressure, pride, and the desire to look good" motivates a number of individuals in business organizations (Porter, 1998).

The other aspects of our study, including Cognitive, Relationship, and Affect, demonstrated a positive influence on sharing both tacit and explicit knowledge. In the original study, however, Cognitive influenced sharing neither explicit nor tacit knowledge. This is an interesting difference and might be explored by examining the role of tacit knowledge in both countries. Tacit knowledge has greater importance in China than in the west because Chinese organizational knowledge is mostly tacit and contextual (Burrows et al., 2005), whereas it is the opposite in the US. In our study, our results demonstrate that appreciation of skills and experience (Cognitive) positively influences all types of knowledge sharing. To explain this in western cultural terms, we suggest that cognitive skills promote social capital, which in turn leads to increased knowledge exchange (Chiu et al., 2006; Wasko and Faraj, 2005).

Our study revealed a positive association between knowledge sharing (both tacit and explicit) and the Relationship construct. This is another confirmation of a long-held assumption in the knowledge management literature that people are more likely to share knowledge with those with whom they have a relationship (Ma and Agarwal, 2007; Coleman, 1988). For example, US firms doing business in China found that building relationships among employees aided tacit knowledge transfer and was more effective than using manuals and other forms of codified knowledge transfer (Burrows et al., 2005). Both the original and replication studies demonstrated Affect as an indication of sharing knowledge, giving Chinese and US students common ground. It appears that if you like someone and care about them, you will help teach them, regardless of your culture. This may be considered obvious, but we find it reassuring to confirm this commonality between cultures.

Our results may help explain some social differences between US individuals working/studying in China and Chinese individuals working/studying in the US. The implications suggest that not only business schools, but managers in multinational corporations sensitize themselves to Guanxi effects (Murray and $\mathrm{Fu}, 2016)$. Multi-cultural groups may experience slower progress due to less knowledge sharing when members do not share Guanxi. Non-Chinese employees may misunderstand Guanxi or confuse it as being part of a clique, causing ill will or mistrust between Chinese and non-Chinese work groups. Chinese teams with high levels of Guanxi may feel hurt or offended by naïve team members outside of the Guanxi network. US workers may expect their personal cognitive aspects to count heavily in knowledge sharing and may be confused when Chinese team-mates do not share. Understanding Guanxi is a critical aspect for companies doing business in China, hiring Chinese employees, or universities educating Chinese students. Likewise, it is equally important for Chinese organizations working with other cultures to understand others' lack of Guanxi awareness.

The limitations of our study primarily lie in common method variance (CMV) issues because we collected the data for dependent and independent variables simultaneously. To detect and control for CMV, we applied the Latent Common Method Variable (LCMV) approach suggested by Liang et al. (2007). The results demonstrated that the average percentage of item variance attributed to the LCMV was below 5\%, whereas the average percentage of item variance attributed to the study's constructs was over $90 \%$, indicating that our study does not present significant CMV issues (Liang et al., 2007). Qualitatively, our use of the original survey translation may have led to respondent confusion. It is possible that a new 
translation may provide some differences in results. Our selection of respondents may have also provided some differences in results, as our group included mostly undergraduates and the original study used MBA students with work experience.

Future research might include another replication with a revised survey to reflect westernized perspectives of Face-Saving and Face-Gaining. We believe that there are some aspects of Guanxi in western culture, but it will take further research to tease out these parallels. Finding commonalities between cultures aids understanding between individuals and promotes both intra- and inter-organizational success (Adler and Gundersen, 2007). We also suggest additional cross-cultural study to explore Guanxi in international settings, determine how to increase Guanxi understanding in non-Chinese organizations, and develop ways for multi-national team members to become part of a Guanxi network. As Chinese organizations continue to do business with firms around the world, it behooves practitioners and researchers to understand the phenomenon of Guanxi and leverage the benefits it can provide, especially in terms of knowledge sharing.

In conclusion, we use replication as a means to further explore the complex topic of what influences people's intention to share knowledge. Specifically, we look at four areas that impact knowledge sharing: Cognitive, Affect, Face gaining/saving and Guanxi (or Relationship). Our survey seeks to measure the intention to share both tacit and explicit knowledge in regards to our constructs. Our results differed from the original study in two areas: Cognitive and Face gaining/saving. Affect and Guanxi (or Relationship) provided similar results in both studies. We find that Face-Gaining and Face-Saving are not as relevant to the US respondents, while Cognitive is more important to US respondents. This is the opposite of the original study and demonstrates differences between Chinese and US business culture. Affect rated similarly between both studies, indicating that when people care about each other, they share knowledge, regardless of their cultural orientation. These results serve to inform researchers and practitioners working with mixed US and Chinese organizations and teams and provide insight to manage and improve working relationships.

\section{References}

Adler, N. J., \& Gundersen, A. (2007). International dimensions of organizational behavior, Cengage Learning.

Brandt, M. J., IJzerman, H., Dijksterhuis, A., Farach, F. J., Geller, J., Giner-Sorolla, R., Grange, J. A., Perugini, M., Spies, J. R., \& van 't Veer, A. (2014). The replication recipe: What makes for a convincing replication? Journal of Experimental Social Psychology, 50, 217-224.

Burrows, G. R., Drummond, D. L., \& Martinsons, M. G. (2005). Knowledge management in China. Communications of the ACM, 48(4), 73.

Chen, C. C., Chen, X.-P., \& Huang, S. (2013). Chinese guanxi: An integrative review and new directions for future research. Management and Organization Review, 9(1), 167-207.

Child, J., \& Möllering, G. (2003). Contextual confidence and active trust development in the Chinese business environment. Organization Science, 14(1), 69-80.

Chin, W. W. (1998). The partial least squares approach to structural equation modeling. in Modern Methods for Business Research (pp.295-336). Psychology Press.

Chiu, C.-M., Hsu, M.-H., \& Wang, E. T. G. (2006). Understanding knowledge sharing in virtual communities: An integration of social capital and social cognitive theories. Decision Support Systems, 42(3), 1872-1888.

Cohen, J. (1992). A power primer. Psychological Bulletin, 112(1), 155-159.

Coleman, J.S. (1988). Social capital in the creation of human capital. American Journal of Sociology, 94 , 95-120.

Dennis, A., \& Valacich, J. (2014). A replication manifesto. AIS Transactions on Replication Research, 1(1), 1-4. 
Ding, L., \& Li, H. (2012). Social networks and study abroad - The case of Chinese visiting students in the US. China Economic Review, 23(3), 580-589.

Elangovan, A. R., \& Shapiro, D. L. (1998). Betrayal of trust in organizations. Academy of Management Review, 23(3), 547-566.

Fornell, C., \& Larcker, D. F. (1981). Evaluating structural equation models with unobservable variables and measurement error. Journal of Marketing Research, 18(1), 39-50.

Fulmer, C. A., \& Gelfand, M. J. (2012). At what level (and in whom) we trust: Trust across multiple organizational levels. Journal of Management, 38(4), 1167-1230.

Guthrie, D. (1998). The declining significance of guanxi in China's economic transition. The China Quarterly, 154, 254-282.

Hair, J., Hult, G. T. M., Ringle, C. M., \& Sarstedt, M. (2016). A primer on partial least squares structural equation modeling, (2nd ed.), Los Angeles: SAGE Publications, Inc.

Hair, J., Sarstedt, M., Hopkins, L., \& Kuppelwieser, V. (2014) Partial least squares structural equation modeling (PLS-SEM): An emerging tool in business research. European Business Review, 26(2), 106-121.

Huang, Q., Davison, R. M., \& Gu, J. (2011). The impact of trust, guanxi orientation and face on the intention of Chinese employees and managers to engage in peer-to-peer tacit and explicit knowledge sharing. Information Systems Journal, 21(6), 557-577.

Hwang, K. (1987). Face and favor: The Chinese power game. American Journal of Sociology, 92(4), 944974.

Keltner, D., \& Anderson, C. (2000). Saving face for Darwin: The functions and uses of embarrassment. Current Directions in Psychological Science, 9(6), 187-192.

Liang, H., Saraf, N., Hu, Q., \& Xue, Y. (2007). Assimilation of enterprise systems: The effect of institutional pressures and the mediating role of top management. MIS Quarterly, 31(1), 59-87.

Ma, M., \& Agarwal, R. (2007). Through a glass darkly: Information technology design, identity verification, and knowledge contribution in online communities. Information Systems Research, 18(1), 42-67.

Murray, J. Y., \& Fu, F. Q. (2016). Strategic guanxi orientation: How to manage distribution channels in China? Journal of International Management, 22(1), 1-16.

Niederman, F., \& March, S. (2015). Reflections on replications. AIS Transactions on Replication Research, 1(1), 1-16.

Nonaka, I. (1994). A dynamic theory of organizational knowledge creation. Organization Science, 5(1), 1437.

Park, S. H., \& Luo, Y. (2001). Guanxi and organizational dynamics: Organizational networking in Chinese firms. Strategic Management Journal, 22(5), 455-477.

Popper, K. (2005). The logic of scientific discovery, Routledge.

Porter, M. E. (1998). Clusters and the new economics of competition. Harvard Business Review, 76(6), 77-90.

Wang, C. L., Siu, N. Y. M., \& Barnes, B. R. (2008). The significance of trust and renqing in the long-term orientation of Chinese business-to-business relationships. Industrial Marketing Management, Korean Economic Growth and Marketing Practice Progress, 37(7), 819-824.

Washington, M., \& Zajac, E. J. (2005). Status evolution and competition: Theory and evidence. Academy of Management Journal, 48(2), 282-296.

Wasko, M.M., \& Faraj, S. (2005) Why should i share? Examining social capital and knowledge contribution in electronic networks of practice. MIS Quarterly, 29(1), 35-57.

Zaheer, A., McEvily, B., \& Perrone, V. (1998). Does trust matter? Exploring the effects of interorganizational and interpersonal trust on performance. Organization Science, 9(2), 141-159. 


\section{Appendix A: Survey Questions and Measurement Items}

\begin{tabular}{|c|}
\hline Table A1. Survey Questions and Measurement Items \\
\hline All questions used a 7 point Likert scale. \\
\hline Face-Saving: (Cheung et al., 2001) \\
\hline 1 I am usually very particular about the way I dress because I do not want others to look down on me. \\
\hline 2 I feel a loss of face when others turn down my favor. \\
\hline Face-Gaining: (Huang et al. 2011) \\
\hline 1 Sharing knowledge with my colleagues will make me gain face \\
\hline 2 I would like to share my knowledge in public, because it will make me gain face \\
\hline Guanxi (Relationship) Orientation: (Zuo, 2002) \\
\hline 1 We expect that our friends will help us in our social life \\
\hline 2 Society is composed of a kind of personal relationship net \\
\hline 3 I enjoy life that includes human concern and kindness \\
\hline 4 Personal relationship is an important resource in career development \\
\hline 5 People should get on with each other harmoniously \\
\hline 6 I will try to build a good relationship with my colleagues and supervisors. \\
\hline Affect-based trust (McAllister, 1995) \\
\hline 1 I have a sharing relationship with the members of my work team. We can all freely share our ideas. \\
\hline 2 I can talk freely with my colleagues about difficulties I am having with my work. \\
\hline $\begin{array}{l}3 \text { If one of the members of my work team was transferred to work in a different team, I would feel } \\
\text { unhappy because I enjoy working with them all. }\end{array}$ \\
\hline $\begin{array}{l}4 \text { If I share my problems with my team members, I know that they will respond constructively and } \\
\text { caringly. }\end{array}$ \\
\hline $\begin{array}{l}5 \text { I believe that the members of my work team have made considerable emotional investments in our } \\
\text { working relationship. }\end{array}$ \\
\hline Cognition-based trust (McAllister, 1995) \\
\hline 1 My colleagues approach their work with professionalism and dedication. \\
\hline 2 I believe that my colleagues are well prepared and competent to do their work. \\
\hline 3 I can rely on my colleagues not to make my job more difficult by careless work. \\
\hline 4 I trust and respect my colleagues. \\
\hline 5 I consider my colleagues to be trustworthy. \\
\hline Intention to share explicit knowledge (Bock et al., 2005) \\
\hline $\begin{array}{l}1 \text { I will share my work reports and official documents with members of my organization more frequently in } \\
\text { the future. }\end{array}$ \\
\hline 2 I will always provide my manuals, methodologies and models for members of my organization. \\
\hline Intention to share tacit knowledge (Bock et al., 2005) \\
\hline $\begin{array}{l}1 \text { I intend to share my experience or know-how from work with other organizational members more } \\
\text { frequently in the future. }\end{array}$ \\
\hline
\end{tabular}




\section{Table A1. Survey Questions and Measurement Items - Continued}

2 I will always provide my know-where or know-whom at the request of other organizational members.

3 I will try to share my expertise from my education or training with other organizational members in a more effective way. 


\section{About the Authors}

Jordana George. Jordana George is a doctoral candidate in Information Systems at Baylor University. She holds an MBA from Penn State University and an MFA from the University of California at Davis. A former manager in client services, technical support, and general management at technology companies and educational institutions, she researches how data, information, and knowledge impact individuals, organizations, and society.

Jie (Kevin) Yan. Jie (Kevin) Yan is an assistant professor in the IS department at Dalton State College. Before joining Dalton State College, Kevin received his Ph.D. degree in MIS from Baylor University and possessed over 6 years of work experience in the Telecom and Datacom industries. He worked for companies such as Cisco and GE. His research focuses on IT consumerization and online user innovation communities.

Copyright $@ 2017$ by the Association for Information Systems. Permission to make digital or hard copies of all or part of this work for personal or classroom use is granted without fee provided that copies are not made or distributed for profit or commercial advantage and that copies bear this notice and full citation on the first page. Copyright for components of this work owned by others than the Association for Information Systems must be honored. Abstracting with credit is permitted. To copy otherwise, to republish, to post on servers, or to redistribute to lists requires prior specific permission and/or fee. Request permission to publish from: AIS Administrative Office, P.O. Box 2712 Atlanta, GA, 30301-2712 Attn: Reprints or via email from ais@aisnet.org. 